\title{
Firm's Absorptive capacity: the case of Vietnamese manufacturing firms
}

Hoang Duong VU ${ }^{1,2}$

\begin{abstract}
Absorptive capacity is an essential factor for the development of any firm. Hence, numerous researchers use it when proposing different approaches and measurements. However, due to the ambiguity of definition of absorptive capacity, some studies focused on the within-firm aspects of absorptive capacity while some looked at the inter-firm aspects. Consequently, there are several proxies for absorptive capacity, which are unlikely to reach an agreement. Therefore, this study aims for the simplified measurement by defining the absorptive capacity of a firm as the gap in persistent efficiency between the firm and the best foreign firm in the same industry. The persistent efficiency of a firm is estimated by using single stage maximum likelihood method. This measurement is applied to the case of Vietnamese manufacturing firms from 2007 to 2015 to estimate the domestic absorptive capacity. The results show that domestic firms in the manufacture of tobacco products sub-sector have the best absorptive capacity and the manufacture of beverages sub-sector have the worst one. Finally, the validity of the proxy is confirmed when the study finds the positive correlation between absorptive capacity and a firm's age, size, technology level and skills of its workers.
\end{abstract}

Key words: Absorptive capacity, Persistent efficiency, Vietnamese manufacturing firms.

JEL classification: D240

Received: 24 April 2018 / Accepted: 1 August 2018 / Sent for Publication: 3 September 2018

\section{Introduction}

Absorptive capacity is crucial for the development of firms and hence various studies examine the importance and contribution of this factor (Bodman \& Le, 2013; Cohen \& Levinthal, 1989; Fosfuri \& Tribo, 2008; Lane \& Lubatkin, 1998; Zahra \& George, 2002). The most cited definition of absorptive capacity is the one of Cohen \& Levinthal (1989), stating that it is the capability of a firm to recognize, learn and apply new knowledge into the operation and production. Successively, many authors use the definition and attempt to analyze absorptive capacity in their own ways. For example,

\footnotetext{
${ }^{1}$ PhD. candidate in Tomas Bata University in Zlin, nam. TGM 5555, 76001 Zlin, Czech Republic; email: hoangduongvu87@gmail.com.

${ }^{2}$ Researcher in Vietnam Institute of Economics, Vietnam Academy of Social Sciences, number 1 Lieu Giai st., Ba Dinh, Hanoi, Vietnam; email: hoangduongvu87@gmail.com

(C) 2018 by the authors; licensee Review of Economic Perspectives / Národohospodářský obzor, Masaryk University, Faculty of Economics and Administration, Brno, Czech Republic. This article is an open access article distributed under the terms and conditions of the Creative Commons Attribution 3.0 license, Attribution - Non Commercial - No Derivatives.
} 
Zahra \& George (2002), based on the root definition of Cohen \& Levinthal, develop a reconceptualization of absorptive capacity. The authors argue that absorptive capacity can have four interconnected dimensions: acquisition, assimilation, transformation and exploitation. Lane, Koka, \& Pathak (2006) meta-analyze the literature on absorptive capacity and suggest a modified definition of absorptive capacity. The authors claim that there should be three stages of utilizing external knowledge: the first one is to identify and understand the new knowledge via empirical studying, the second one is to adapt new knowledge into practice, and the final one is to create new knowledge based on what has been learned (Lane et al., 2006, p. 856). Respectively, there are various proxies for absorptive capacity (such as R\&D intensity, R\&D expenditures, patents, human capital or technology gap) which are unlikely to reach an agreement.

Therefore, the present study contributes another proxy that can simplify the measurement of absorptive capacity. The absorptive capacity of a firm is considered the capability gap between this firm and the best firm in the same industry. The main interest of the paper is the capability of domestic firms to absorb benefits from foreign firms ${ }^{3}$. Therefore, the gap in capability here is the gap between domestic firms and the best foreign firm in the industry. It can be considered as foreign direct investment (FDI) absorptive capacity. Instead of trying to break down the capability of a firm into various dimensions, the paper simplifies the issue by measuring it as the persistent efficiency of firms. According to Kumbhakar, Lien, \& Hardaker (2014), the persistent efficiency and residual efficiency are components of technical efficiency. While the residual efficiency is the short-term effect and may not occur in the following years, the persistent efficiency is the long-term factor and it is unlikely to change unless a big chance in the industry or in the management mechanism happens. Therefore, persistent efficiency could be a good proxy for internal capability, which is firm-specific. Then, the relative gap in persistent efficiency between one firm and the best foreign firm in the same industry is used to proxy for absorptive capacity of the domestic firm.

Note that this method to measure absorptive capacity might be applied to any country and region where foreign firms play an important role in economic development, including Central and East European countries or East Asian countries. If the absorptive capacity of domestic firms is weak, it means the domestic firms are unable to gain much from cooperating with foreign partners. Then the market may be dominated by the foreign firms. In order to check the validity of the proxy, the paper applies to Vietnamese manufacturing firms. Vietnam is an emerging economy where firms are a catalyst for the economic development. The manufacturing sector contributes significantly to the industrial performance. However, there are many obstacles which hamper the development of business section, including poor business environment, nothigh technology level or poor managerial skills etc. (Tran, Pham \& Vu, 2014). Additionally, the economic development of Vietnam seems to depend on foreign firms and Vietnam lacks big companies that could lead the market. Hence, Vietnam needs improving the capabilities of domestic firms to compete with foreign counterparts. Otherwise it could be stuck in the middle-income trap. Consequently, it is vital to identify the capability of domestic firms as a base for further development progress.

\footnotetext{
${ }^{3}$ Foreign firms are firms where foreign investors hold more than $50 \%$ of the charter capital.
} 
Therefore, the author believes that Vietnam is a good case to apply this measurement for absorptive capacity at firm level.

The paper is organized as follows. The next part generally provides the theoretical background of the study by reviewing the definitions and measurements of absorptive capacity before going to the concept of persistent efficiency. The third part discusses in detail the methodology to measure absorptive capacity and application in the case of Vietnam. It is followed by the findings and conclusion parts.

\section{Theoretical background}

\subsection{Definitions and approaches of absorptive capacity}

The term "absorptive capacity" is was first used by Cohen \& Levinthal (1989) in the close relationship with R\&D activities of firms. However, R\&D activity is not the same as absorptive capacity. R\&D creates not only innovation but also capability of a firm to "identify, assimilate and exploit knowledge from the environment" (Cohen \& Levinthal, 1989 , p. 569) and the authors firstly define this capability as a firm's absorptive capacity. Essentially, the absorptive capacity is a prerequisite for firms to generate new knowledge. Then, Cohen \& Levinthal (1990) slightly revise the definition of absorptive capacity as "the ability of a firm to recognize the value of new, external information, assimilate it and apply it to commercial ends" (Cohen \& Levinthal, 1990, p. 1). Absorptive capacity requires the prior related knowledge. It implies that in order to learn new skills, knowledge or technique, the worker (at the individual level) and the firm (at the organizational level) should already have a related background on the skills, knowledge or technique. Certainly, the absorptive capacity of a firm depends on the absorptive capacity of its members. However, it is not a simple summation; it also depends on the internal organization of this firm. At any level, Cohen \& Levinthal (1990) underline the importance of prior knowledge. The authors argue that absorptive capacity is cumulative and therefore the "richer" prior related knowledge is, the better is absorptive capacity. Additionally, absorptive capacity can help a firm to predict a new technological trend that could create new business opportunities (Cohen \& Levinthal, 1994).

In fact, the definition of absorptive capacity of Cohen \& Levinthal is ambiguous. Consequently, there are various studies that have re-defined and developed it. Some of them focus on the within-firm aspect of absorptive capacity. Szulanski (1996) argues that internal knowledge transfer is crucial to create the comparative advantage of firms. Zahra \& George (2002), based on Cohen \& Levinthal's definition, state that absorptive capacity is a dynamic capability that directly affects the competitiveness of a firm. The authors put forward a new reconceptualization of this term. Then, absorptive capacity of firms is divided into four dimensions that are interdependent on each other. They are acquisition, assimilation, transformation and exploitation. Zahra \& George (2002) group acquisition and assimilation into the potential absorptive capacity that relates to the capability of a firm to identify and acquire new knowledge. Nevertheless, the potential absorptive capacity does not ensure that the firm could apply new knowledge in practice. Therefore, it is necessary to have the realized absorptive capacity (which includes transformation and exploitation). The authors state that absorptive capacity depends not only on prior knowledge, but also on knowledge complementarity and 
knowledge resources diversification. Tu, Vonderembse, Ragu-Nathan, \& Sharkey (2006) support the perspective that underlines the importance of internal knowledge development and suggest a broader definition, stating that absorptive capacity should be an organizational mechanism that helps to identify an assimilate both internal and external knowledge and apply it to improve the productivity of a firm. Martinkenaite \& Breunig (2015) also examine the importance of the firm-level absorptive capacity and argue that individual and organizational absorptive capacity are different. Then, a firm's absorptive capacity requires the interaction between micro level (individual) and macro level (firm).

From another perspectives, some papers value the importance of inter-firm factors when studying the absorptive capacity of firms. Lane \& Lubatkin (1998) pay attention to the relative absorptive capacity, claiming that a firm has the same starting point to learn new knowledge as long as this firm can choose the appropriate partners. Lane \& Lubatkin (1998) shift the analysis to external learning of firms. More specifically, the "student" firm can learn more effectively from the "teacher" firm if they share some common characteristics and the student firm somehow has a sound background about new knowledge offered by the teacher firm. This argument to some extent coincides with the idea of Dyer \& Singh (1998). Dyer \& Singh (1998) state that inter-firm factors are essential to improve the absorptive capacity and competitive advantages of a firm. It implies that the firm could enhance its competitiveness by making use of the relationship with partners at some specific stages including resources utilizing, knowledge sharing and asset supplementing.

Generally, there is a consensus that absorptive capacity is an important factor that can improve productivity of any firm. However, while some authors only analyze the within-firm structure and mechanism to develop and transfer internal knowledge, some believe that it is more important to analyze the inter-firm mechanism to improve the absorptive capacity of a firm. Respectively, there are many proxies to measure the absorptive capacity of firms. Many papers used $R \& D$ - related variables to represent for absorptive capacity, such as R\&D intensity (Behera, 2015; Mowery \& Oxley, 1995; Tsai, 2001), R\&D expenditures (Girma, Gorg, \& Pisu, 2008; Silajdzic \& Mehic, 2015) or patents (Ahuja \& Katila, 2001). However, the findings are not consistent. For instance, Tsai (2001) found that absorptive capacity (proxied by R\&D intensity) have positive effect on productivity, meanwhile Mowery \& Oxley (1995) also used R\&D intensity but concluded that it did not positively influence the external learning capability. Apart from R\&D proxies, Martinkenaite \& Breunig (2015) used human capital (ratio of white-collar workers to total employment) to represent the absorptive capacity and Flôres, Fontoura, \& Guerra Santos (2007), Jabbour \& Mucchielli (2007), and Imbriani, Pittiglio, Reganati, \& Sica (2011) measured absorptive capacity by the technology gap among firms. The technology gap was presented by TFP, but TPF could include anything but production inputs, such as labor and capital, so that it would not be the best proxy for absorptive capacity.

Absorptive capacity is a broad definition that could include various factors. Hence, attempting to proxy absorptive capacity by considering different parts of it (intra firms and inter firms) seems to have limitations. The author believes that it is better to consider both inter-firms and intra-firms factors when measuring the absorptive capacity of firms. Firstly, the intra-firm factors are included in the capability of firms. The 
capability here is the internal factors, which are not labor and capital, and the measurement is discussed in detail in the next sections. Secondly, the external factors are examined by considering the gap between domestic firms and foreign firms. The study agrees with the argument that the student firm can learn better from the teacher firm if they are sharing some common knowledge and characteristics. Then, it premises that firms in the same industry could have more chance to learn from each other than from firms in another industry. Therefore, absorptive capacity of a firm is the distance from its firm-specific-capability to the top firm-specific-capability firms in the same industry. Now the question is how to quantify the firm-specific capability. This study suggests that the appropriate proxy could be derived by analyzing the technical efficiency of a firm.

\section{Technical efficiency}

Technical efficiency is not a new concept and there are substantial studies estimating this factor for different purposes. Most of them estimated technical efficiency to measure the performance of firms (Farrell, 1957; Badunenko, Fritsch, \& Stephan, 2006; Feng \& Wu, 2006; Greene, 2005; Ghali \& Rezgui, 2011; Battese \& Coelli, 1992, 1995, 1988). In Vietnam, there are a few papers on this issue and majority of them attempted to capture the productivity of firms (Minh, Long, \& Thang, 2007; H.D. Vu, 2016). Only Vu \& Le (2017) use technical efficiency to proxy for absorptive capacity. However, the authors were unable to decompose the technical efficiency that could lead to an upward or downward bias. Based on this idea, the study separates the firm effects, persistent efficiency and time-varying efficiency when calculating technical efficiency.

Firms must transform inputs to outputs by using the "black box" production function. The production function represents the technology to produce final products. If $\mathrm{y}$ is $\mathrm{m}$ multidimensional non-negative vector of output and $\mathrm{x}$ is $\mathrm{n}$-multidimensional nonnegative vector of inputs, the relationship can be presented by the technology function $\mathrm{f}($.$) as follows:$

$$
y=f(x) \equiv f\left(x_{1}, \ldots x_{n}\right)
$$

The production function per se describes the maximum amount of outputs produced given certain level of inputs by using current level of technology and it is the frontier of the feasible production set. Therefore, a production plan of any firm is technically inefficient if it is not on the frontier. In the Figure 1, point A is technically inefficient because it is a loss of $\mathrm{AB}$ outputs given the same inputs or a waste of $\mathrm{AC}$ inputs given the same outputs.

There are two types of technical efficiency: input-oriented and output-oriented technical efficiency. This paper only deals with the second one and it is mathematically presented by:

$$
y=f(x) * e^{-u}
$$

Where $\mathrm{u}$ (positive) is output-oriented technical inefficiency and $e^{-u}$ is technical efficiency. Technical inefficiency could be neutral or non-neutral. If it is non-neutral, it is a function of some factors. 


\section{Figure 1. Production function curve}

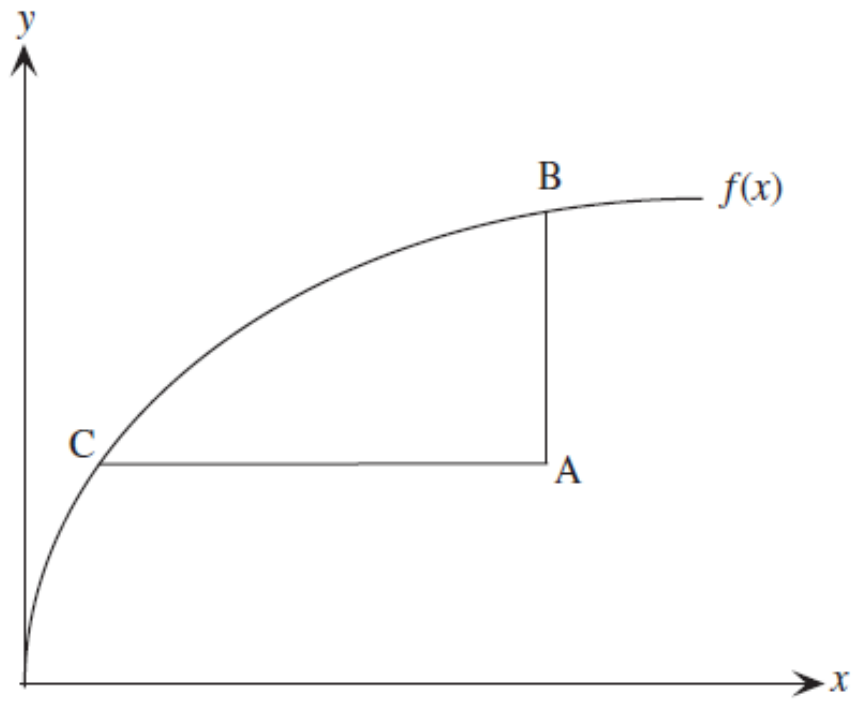

\section{Source: Author}

In order to proxy for absorptive capacity, it is necessary to examine technical efficiency in the panel data. One observation can be repeated several times and then panel data allows us to consider heterogeneity. More importantly, the panel data might show if the technical inefficiency is persistent over time or if it is time-variant.

The classic model assumed technical inefficiency is individual specific and timeinvariant:

$$
\begin{aligned}
& y_{i t}=f\left(x_{i t} ; \beta\right)+\epsilon_{i t}, \\
& \epsilon_{i t}=v_{i t}-u_{i}, \quad u_{i} \geq 0, i=1, \ldots \ldots, N \& t=1, \ldots \ldots, T
\end{aligned}
$$

$u_{i}$ is time invariant technical inefficiency of individual $i$ and it could be fixed (Schmidt \& Sickles, 1984) or random parameter (George E. Battese \& Coelli, 1988; S. Kumbhakar, 1987). However, the limitation is the time-invariant assumption. It might make sense in the short period, but it also implies that a firm never learn over years. It is unreasonable in reality. Therefore, Cornwell, Schmidt, \& Sickles (1990) put forward the model that includes time-variant factor into technical inefficiency:

$$
\begin{gathered}
y_{i t}=\alpha_{i}+x_{i t}^{\prime} \beta+v_{i t}, \\
\alpha_{i} \equiv \alpha_{0 i}+\alpha_{1 i} t+\alpha_{2 i} t^{2}
\end{gathered}
$$

Where $\alpha$ is firm-specific characteristics and $\mathrm{t}$ is changes over time (time trend). Note that in this model, the efficiency of one firm is relative to the efficiency of the best firm in one year. However, because the time trend is treated as independent variable of $\alpha_{i}$, it 
cannot be included in $x_{i t}^{\prime}$. Therefore, this model does not allow us to separate inefficiency and time trend (or technical change).

Generally, these models could not be split between technical inefficiency and firm heterogeneity, then it might lead to bias in calculating technical efficiency. Additionally, another drawback of the time-variant model is that it is still unable to separate persistent and time-varying inefficiency.

It is desirable to separate firm effects, persistent efficiency and time invariant inefficiency in order to measure absorptive capacity of a firm. Therefore, S. C. Kumbhakar, Lien, \& Hardaker (2014) show the model where the error term is broken down into four components: latent heterogeneity $\mu_{i}$, time-variant inefficiency in shortterm uit ,time-invariant inefficiency (persistent inefficiency) $\rho_{i}$ and random shocks $v_{i t}$. The model is described in detail in the next section. The decomposition is useful and instead of using technical efficiency as a proxy for absorptive capacity, this paper makes use of the availability of persistent (in)efficiency. The component of persistent (in)efficiency is essential in this paper and it is suitable to measure absorptive capacity of a firm. Persistent (in)efficiency represents the management effect and various unobservable inputs that are unlikely to change overtime. It is a good proxy for firmspecific structure and organization, which directly affects the production of a firm. Additionally, persistent efficiency cannot be changed unless there is a big change in the ownership of a firm or a change in institution (such as policy in the industry) (S. C. Kumbhakar, Wang, \& Horncastle, 2015, p. 270). Certainly, if it is inefficiency, it will be the internal obstacle, which any firm wants to minimize. However, it does not make much sense if we consider the persistent (in)efficiency of a single firm. It should be the relative one in the industry. Consequently, absorptive capacity of one firm is measured by the gap between the persistent (in)efficiency of one firm and the best firm in the industry.

Note that this study seeks to provide a simplified and generalized version of absorptive capacity measurement, premising that absorptive capacity of one firm is simply the capability gap between this firm and the best foreign firm. This measurement integrates the intra-firm and inter-firm aspects into one proxy of absorptive capacity. Other proxies, including R\&D intensity, R\&D expenditures, patents or human capital, only reflect the internal capability of firms and do not evaluate much the external interaction of firms. Additionally, although R\&D is important, not every firm has enough resources to invest in $\mathrm{R} \& \mathrm{D}$, especially in the case of less developed or developing countries4. It implies that database is not always available for comparison. Reversely, this proxy based on persistent efficiency can be created for almost all firms with basic data of production inputs, including labor and capital, therefore it is easy to make a comparison across countries. In fact, some papers used the gap in efficiency or TFP to proxy for absorptive capacity (Flôres, Fontoura, \& Guerra Santos (2007), Jabbour \& Mucchielli (2007), Imbriani, Pittiglio, Reganati, \& Sica (2011),H.D.Vu \& Le, (2017)) which are quite similar to the method in this paper. However, persistent efficiency can be a better proxy after removing other noises from it.

\footnotetext{
${ }^{4}$ For example, in case of Vietnam, the database for R\&D at firm level is not available continuously in the Annual Enterprises Survey.
} 
This paper deals with the measurement in the case of Vietnam and estimates FDI absorptive capacity of domestic firms in the manufacturing sector. It assumes that the foreign direct investment firms are more advanced, and they are likely to have better absorptive capacity. Therefore, persistent (in)efficiency of the best FDI firms can be a good benchmark. Consequently, FDI absorptive capacity of domestic firms is defined as the gap between their persistent inefficiency and the best FDI firm. According to the author's knowledge, this paper is the first one using the gap in persistent efficiency to represent the absorptive capacity of a firm. Therefore, it is hard to compare it with the exiting literature. Nevertheless, a good proxy must comply with the basic concept of absorptive capacity, then the validity is checked by examining the correlation of this proxy and other common factors/determinants of absorptive capacity from previous studies.

\section{Methodology}

\subsection{Model specification}

Follow the equation (3) and after decomposing the error term into four components, the model is presented by:

$$
y_{i t}=\alpha_{0}+f\left(x_{i t} ; \beta\right)+\mu_{i}+v_{i t}-\rho_{i}-u_{i t}
$$

Where

$\mu_{i}$ is latent heterogeneity and it is independent and identical distribution $\mathrm{N}\left(0, \delta_{\mu}^{2}\right)$,

$\rho_{i}$ is persistent inefficiency and it is i.i.d $N^{+}\left(0, \delta_{\rho}^{2}\right)$,

$v_{i t}$ is a random shock to absorb stochastic effects and it is i.i.d $N\left(0, \delta_{v}^{2}\right)$,

$u_{i t}$ is time-varying inefficiency in short-term that might not repeat over years and it is i.i.d $N^{+}\left(0, \delta_{u}^{2}\right)$

Kumbhakar, Wang, \& Horncastle (2015) rearrange and estimate the model based on a single stage maximum likelihood method.

$$
y_{i t}=\alpha_{0}^{*}+f\left(x_{i t} ; \beta\right)+\alpha_{i}+\varepsilon_{i t}
$$

Where:

$$
\begin{gathered}
\alpha_{0}^{*}=\alpha_{0}-E\left(\rho_{i}\right)-E\left(u_{i t}\right) \\
\alpha_{i}=\mu_{i}-\rho_{i}+E\left(\rho_{i}\right) \\
\varepsilon_{i t}=v_{i t}-u_{i t}+E\left(u_{i t}\right)
\end{gathered}
$$

$\alpha_{i}$ and $\varepsilon_{i t}$ are distributed $\left(0, \delta^{2}\right)$

$x_{i t}$ in this model includes logarithm of capital and labor of the firm $i$ in the Vietnamese manufacturing firms in time $\mathrm{t}$.

$y_{i t}$ is logarithm of value added of the firm $\mathrm{i}$ in time $\mathrm{t}$.

After conducting some test for identification, the translog production function is preferred to Cobb-Douglas. More specifically, translog is as follow: 


$$
\begin{array}{r}
f\left(x_{i t} ; \beta\right) \equiv \beta_{1 i} \ln _{i t}+\beta_{2 i} \ln l_{i t}+\beta_{3 i}(\ln k * \ln l)_{i t} \\
+\beta_{4 i}(\ln k * \ln k)_{i t}+\beta_{5 i}(\ln l * \ln l)_{i t}
\end{array}
$$

It is possible to estimate $\hat{\beta}$ of the model (8) by fixed or random effect with panel data. In this case, the author chooses fixed effect method after conducting the Hausman test. Then $\widehat{\alpha_{l}}$ and $\widehat{\varepsilon_{l t}}$ are predicted. Next, $\widehat{u_{l t}}$ the time-varying inefficiency could be estimated by using the equation (11) with assumption on distribution of $u_{i t}$. The residual technical efficiency then is $\exp \left(-u_{i t} \mid \varepsilon_{i t}\right)$. Then, it is possible to estimate the persistent inefficiency (PI) $\rho_{i}$ from the equation (10) and persistent technical efficiency is $\exp \left(-\rho_{i}\right)$. Finally, the technical efficiency equals residual technical efficiency times persistent technical efficiency. This method follows the approach of Kumbhakar, Lien, $\&$ Hardaker (2014).

Note that this paper focuses on the importance of persistent (in)efficiency and residual (in)efficiency, not the overall technical (in)efficiency. It is expected that in the same industry, the FDI firms are likely to perform better and then the gap between domestic firms and FDI firms is a proxy for absorptive capacity of the domestic firms:

$$
D C_{i t}=\frac{\max (F P E)-D P E_{i t}}{\max (F P E)}
$$

$D C_{i t}$ is domestic capacity of the domestic firm i in year t, $D P E_{i t}$ is persistent efficiency of the domestic firm $\mathrm{i}$ in year $\mathrm{t}$ and $\max (\mathrm{FPE})$ is the maximum value of persistent inefficiency of FDI firm in year $t$ in the same industry. The lower value of DC indicates the better absorptive capacity of the firm.

\subsection{Database}

Panel data is created from the Annual Vietnamese Enterprises Survey from 2007 to 2015. This period covers many important events from Vietnamese economy. Since 2007, Vietnam has officially joined WTO and has become a potential destination for foreigner investors. Unfortunately, after two years, the global financial crisis occurred and hampered majority of economies worldwide. After 2010, the global economy and Vietnam somehow started recovering from the economic crisis and the business environment has been gradually stabilized. Therefore, performance of firms during this hard time can reflect their capability in the best way.

The panel data includes 52435 observations over eight years and it is unbalanced panel data. Data summary is in the Appendix C.

From the Annual Vietnamese Enterprises Survey, some major variables are taken. K is fixed capital for production of a firm (million VND), $\mathrm{L}$ is total labor for production of this firm (person) and $\mathrm{Y}$ is value added of the firm (million VND) which is calculated by income approach. During the period from 2007 to 2015, only firms that appear at least 7 times are chosen to avoid the interruption of the database. All variables are transformed by using a logarithm. 


\section{Findings and discussions}

Before estimating efficiency, it is necessary to conduct some specification tests, including the test for the form of production function (Cobb-Douglas or Translog production function), the test for time-variant inefficiency vs. time-invariant inefficiency and the test for fixed effect vs. random effect method. The maximum likelihood test results in the Table 1 show that the translog production function, timevariant efficiency are preferred over Cobb-Douglas and time-invariant and the Hausman test reveals that fixed effect model is better than random effect in this model (Table 2).

At the first stage, the model (8) is regressed by using fixed effect with panel data (find table of result in the Appendix A). Then, persistent efficiency and residual efficiency are estimated based on the method of Kumbhakar, Lien, \& Hardaker (2014). Note that the study only focuses on these two factors rather than the overall technical efficiency because the gap in persistent efficiency between domestic firms and foreign firms is defined as absorptive capacity of the former.

Table 1. Maximum likelihood test

\begin{tabular}{clll}
\multicolumn{1}{c}{$H_{0}$} & Test statistic & Critical value & Decision \\
\hline Cobb-Douglas $\left(\beta_{3}=\beta_{4}=\beta_{5}=0\right)$ & 28.66077 & 6.483 & Reject \\
Time invariant $\left(\delta_{u}=0\right)$ & 2138.3768 & 3.841 & Reject \\
\hline
\end{tabular}

Source: Author

Table 2. Hausman test

\begin{tabular}{clll}
$H_{0}$ & Hausman test & Critical value & Decision \\
\hline Random effect & 666.98 & 11.07 & Reject \\
\hline
\end{tabular}

Source: Author

It can be noticed easily from the Figure 2 and Figure 3 that the difference between domestic group and foreign group in residual efficiency is not significant. However, while RE of foreign firms tends to increase gradually over years, RE of domestic firms fluctuates around 50\% after an increase from 2007 to 2010. Nevertheless, the RE is only a short-term efficiency and it may not repeat next year for one firm. For instance, one firm receives a huge bonus from lottery and the director decides to use this amount to invest in production. This amount could boost the production in this year but next year the same thing is unlikely to occur. Reversely, persistent efficiency (PE) is unlikely to change unless there is a big change for the whole industry or a change in the ownership or management mechanism of a firm. Interestingly, PE of the foreign group is considerably higher than in the case of the domestic group. From 2007 to 2015, the average PE of foreign firms is $59.53 \%$ and in the case of domestic firms it is only $53.7 \%$. It means that the efficiency difference between the two groups lies on the persistent efficiency. Recall that this indicator is unlikely to change, and it repeats over years. It might imply that a big change in management system of domestic firms is needed to help them converge to the frontier in the industry. 
Figure 2. Residual efficiency

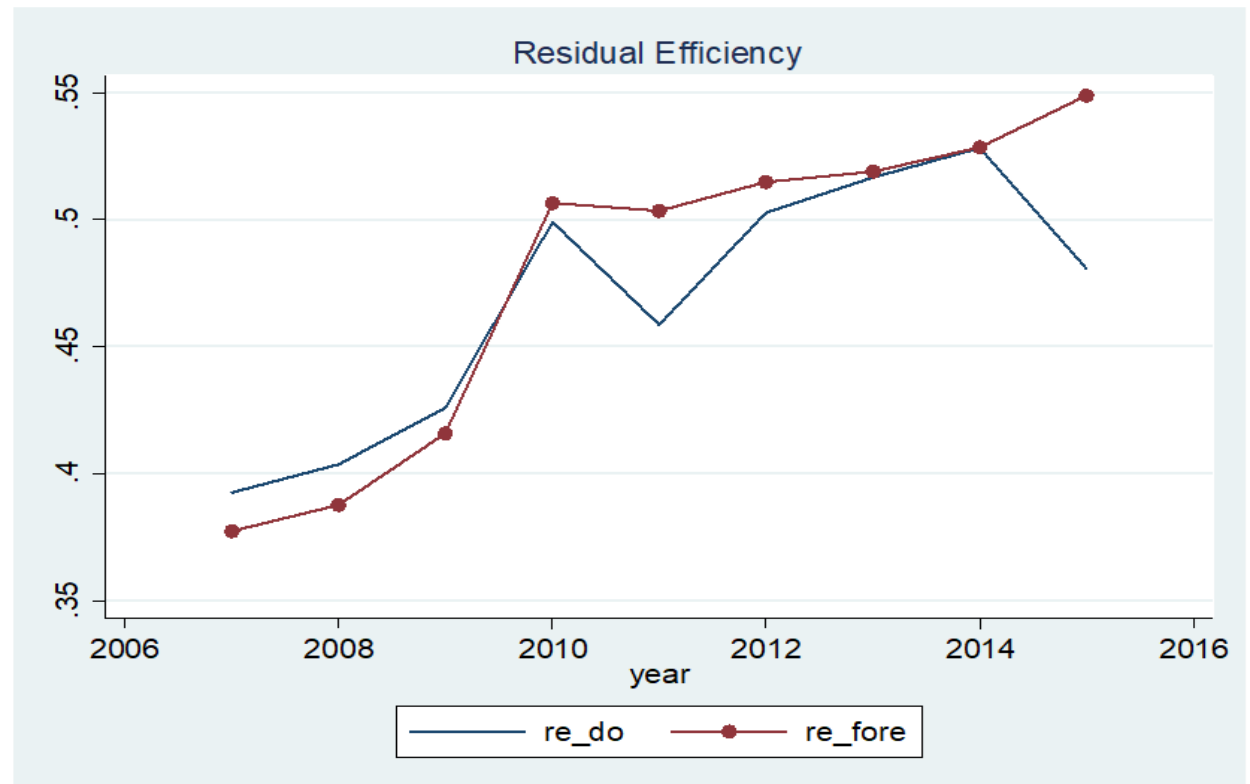

Source: Author

Figure 3. Persistent Efficiency

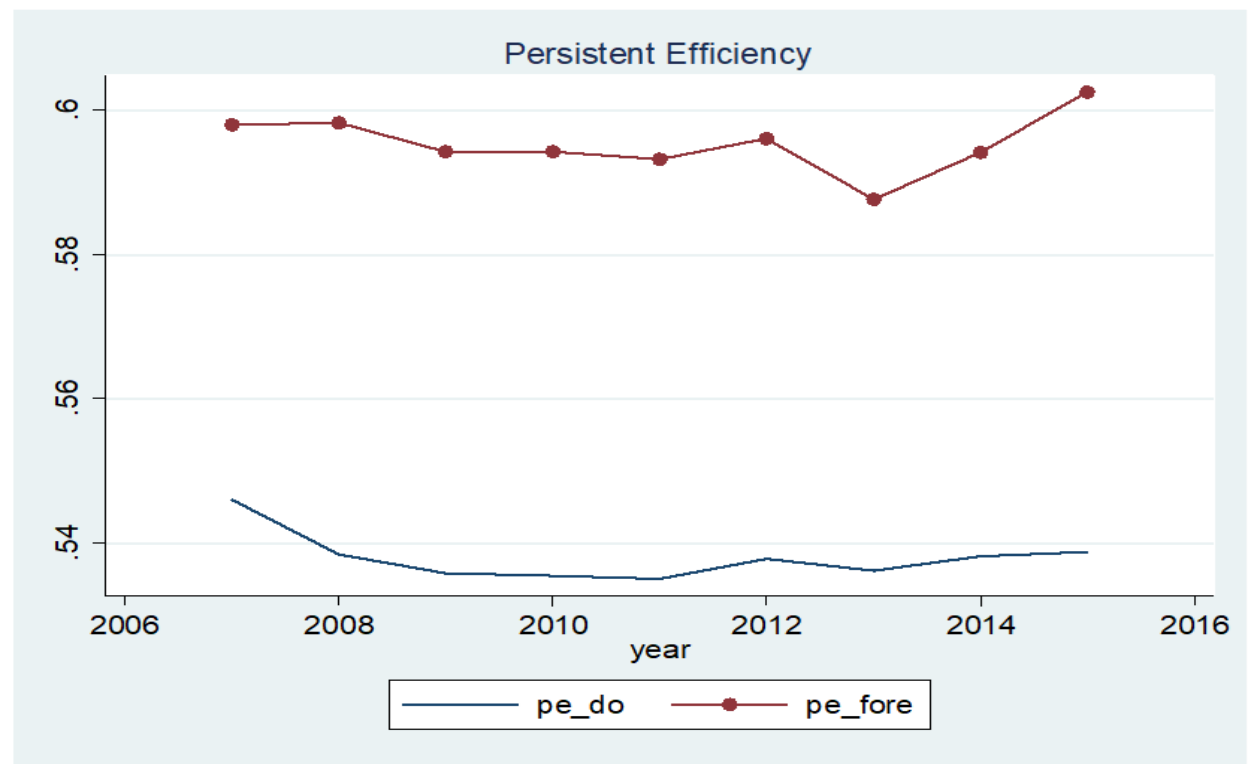

Source: Author 
Then, the PE gap between domestic firms and the best FDI firm could be a proxy for absorptive capacity. The DC of domestic firms is calculated in the equation (13). The manufacturing sector of Vietnam comprises of 23 sub-sectors and the Table 3 presents the mean value of DC of them:

Table 3. Average DC of sub-sectors

\begin{tabular}{|c|c|c|c|c|}
\hline Sub-sector & $\begin{array}{c}\text { Domestic } \\
\text { observation }\end{array}$ & $\begin{array}{c}\text { Mean DC } \\
\text { over years }\end{array}$ & rank & Technology 5 \\
\hline Manufacture of tobacco products & 83 & 0.0889 & 1 & Low \\
\hline Manufacture of coke and refined petroleum & 34 & 0.1318 & 2 & Medium \\
\hline Manufacture of electrical equipment & 984 & 0.2175 & 3 & Medium \\
\hline Manufacture of machinery and equipment n.e.c & 1414 & 0.2591 & 4 & Medium \\
\hline Manufacture of pharmaceuticals, medicinal & 504 & 0.2606 & 5 & High \\
\hline Manufacture of chemicals and chemical products & 1975 & 0.2744 & 6 & Medium \\
\hline Manufacture of motor vehicles; trailers and semitrailers & 267 & 0.2786 & 7 & Medium \\
\hline Manufacture of basic metals & 764 & 0.2908 & 8 & Medium \\
\hline Manufacture of rubber and plastics products & 4928 & 0.2978 & 9 & Medium \\
\hline Manufacture of textiles & 2444 & 0.3134 & 10 & Low \\
\hline Manufacture of computer, electronic and optical & 432 & 0.3329 & 11 & High \\
\hline Manufacture of furniture & 1762 & 0.3368 & 12 & Low \\
\hline Manufacture of fabricated metal products, except & 5121 & 0.3513 & 13 & Medium \\
\hline Manufacture of paper and paper products & 2262 & 0.3539 & 14 & Low \\
\hline Repair and installation of machinery and equipment & 521 & 0.3715 & 15 & Medium \\
\hline Manufacture of other transport equipment & 398 & 0.3725 & 16 & High \\
\hline Manufacture of leather and related products & 1314 & 0.3751 & 17 & Low \\
\hline Other manufacturing & 940 & 0.3770 & 18 & Medium \\
\hline Manufacture of other non-metallic mineral products & 1875 & 0.3839 & 19 & Medium \\
\hline Manufacture of food products & 6124 & 0.3898 & 20 & Low \\
\hline Printing and reproduction of recorded media & 3466 & 0.4064 & 21 & Medium \\
\hline Manufacture of wearing apparel & 4511 & 0.4242 & 22 & Low \\
\hline Manufacture of wood and of products of wood and & 1658 & 0.4369 & 23 & Low \\
\hline Manufacture of beverages & 1313 & 0.5099 & 24 & Low \\
\hline
\end{tabular}

Source: Author

Among these sub-sectors, the manufacture of tobacco products seems to have the best absorptive capacity (with lowest value of average DC over year). The second place is the manufacture of coke and refined petroleum. The following ranks are the equipmentrelated sub-sectors. Interestingly, some important sub-sectors in Vietnam, such as

\footnotetext{
${ }^{5}$ Eurostat classification
} 
textiles and wearing apparel (H.D. Vu, 2016), do not have a good absorptive capacity from 2007 to 2015. Meanwhile, absorptive capacity of the manufacture of motor vehicles, trailers and semitrailers is good with the average DC of 0.2786 (rank 7th). Interestingly, among the top 5 sub-sectors, there are four with medium to high technology level, while among the bottom 5, there are four sub-sectors with low technology level. It implies that firms in the more advanced-technology sub-sectors have better chance to learn from foreign firms. This coincides to some extent with the argument of Cohen and Levinthal (1994) that absorptive capacity depends on the prior knowledge of firms. The firms in the medium and high technology sub-sectors obviously accumulate better knowledge than others and then they could gain more benefits from foreign counterparts. Reversely, the firms in the low technology subsector might struggle to learn due to the poorer accumulated knowledge.

Although the main purpose of the paper is to measure the FDI absorptive capacity of domestic firms, it is interesting to compare it with the absorptive capacity of foreign firms in the same industry. The absorptive capacity of one foreign firm is the gap in PE between this firm and the best foreign firms in the same industry. It refers to the benefits this foreign firm can gain from the top foreign firm. From the Figure 4 we can see that the mean values of DC across all subsectors of foreign firms are always smaller than these of domestic firms (except for the subsector of Repair and installation of machinery and equipment). It implies that absorptive capacity of foreign firms in the manufacturing sector of Vietnam is better than in the case of domestic firms. The difference in the absorptive capacity between domestic and foreign groups might imply a risk for Vietnam's economy. If one foreign firm and one domestic firm learn from the best foreign firm at the same time, the foreign one might gain more benefit due to better absorptive capacity and consequently it can generate more knowledge and products than the domestic one. It means the gap can be larger and larger over years and the domestic sectors are unlikely to compete with the foreign sectors. However, this paper can only show the phenomenon and further study is needed to conclude this issue.

Unfortunately, there is a lack of studies using this method to measure absorptive capacity, hence it is hard to make a comparison on the proxy. Therefore, in order to check the validity of this proxy, the study takes one further step by examining the correlation between this proxy and other relating factors. The key point is that if this is a good proxy of the absorptive capacity of a firm, it should have positive correlations 6 with some important factors which are stated in the previous studies. Various authors argue that absorptive capacity is accumulative. Cohen \& Levinthal (1994) show that cumulativeness is an essential feature of absorptive capacity. The current absorptive capacity of a firm depends on what it has learned before and the future absorptive capacity depends on what it is learning at the moment.

\footnotetext{
${ }^{6}$ Note that, because the lower value of DC implies that better absorptive capacity, the positive correlation here turns out to be negative correlation.
} 


\section{Figure 4. Mean DC of domestic and foreign firms}

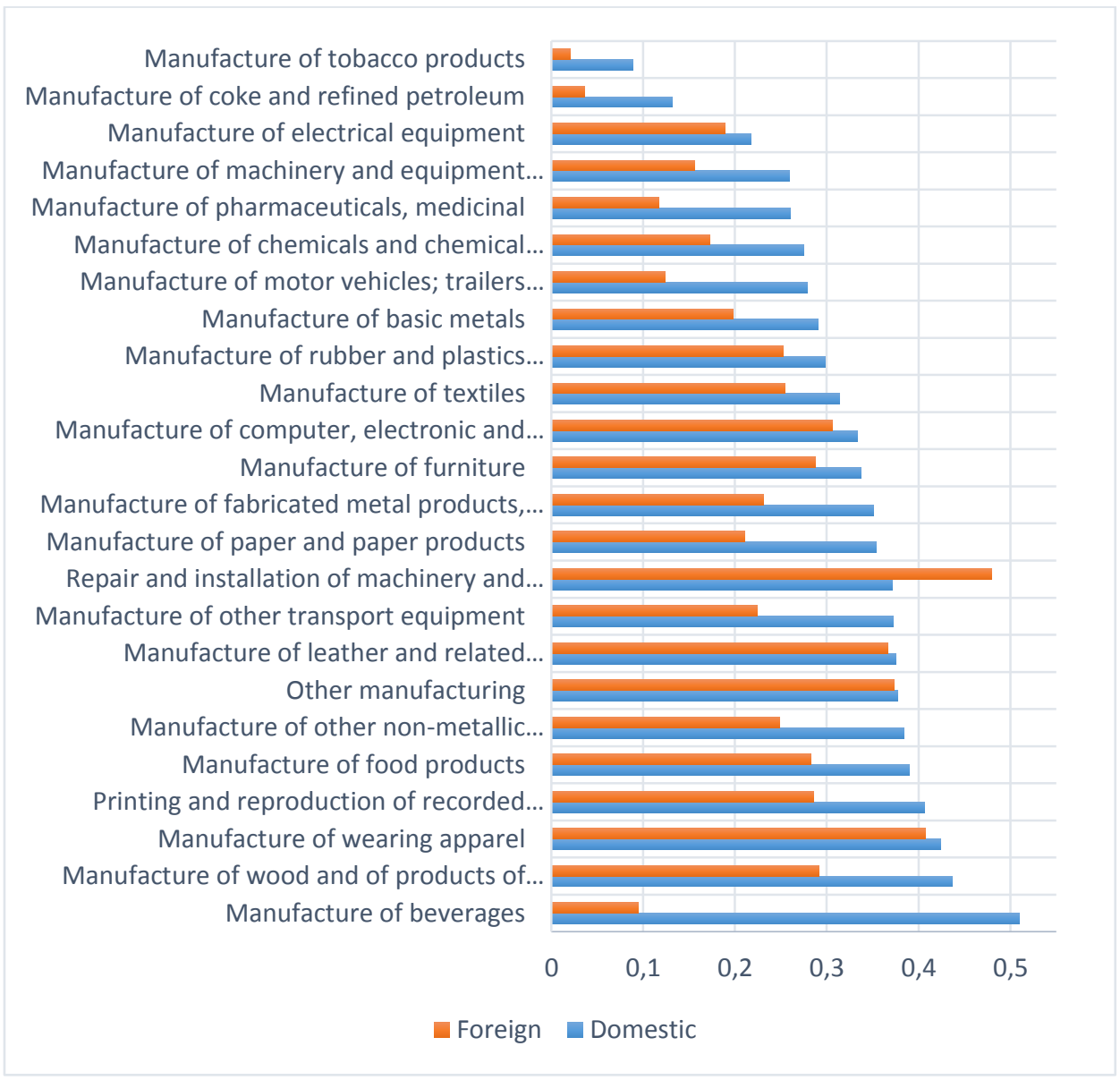

\section{Source: Author}

It implies that there is a positive correlation between absorptive capacity and the age and size of a firm (Mowery \& Oxley, 1995; Rao \& Drazin, 2002; Sørensen \& Stuart, 2000). Additionally, absorptive capacity of a firm differs due to different absorptive capacity of individual members (Cohen \& Levinthal, 1994) and therefore firms with bigger number of skilled-workers might have better absorptive capacity (Martinkenaite \& Breunig, 2015). And certainly, it is expected that a firm that is technologically more advanced could absorb new knowledge faster. Therefore, the association between absorptive capacity and age and size of a firm, skill of its workers and its technological level is expectedly positive. Consequently, a good proxy of absorptive capacity should have the same correlations, otherwise it is unable to be used in further studies. These correlations are examined in the case of Vietnam. 


\section{Absorptive capacity and age and size of a firm}

Correlation between absorptive capacity and age of a firm in the Vietnamese manufacturing sector is significantly negative (correlation is -0.2251). This correlation is shown in the Figure 4. Note that the lower value of DC is, the better absorptive capacity of the firm is. Therefore, it captures a phenomenon that the more experienced firms seems to have better learning capability. Cohen \& Levinthal (1994) argue that preknowledge is important for absorptive capacity and knowledge could be cumulated over times. Firms operating longer in one industry certainly have a better chance to gain more knowledge and consequently, their absorptive capacity is better. This argument is to some extent approved in this case.

Figure 5. Correlation between DC and age of a firm

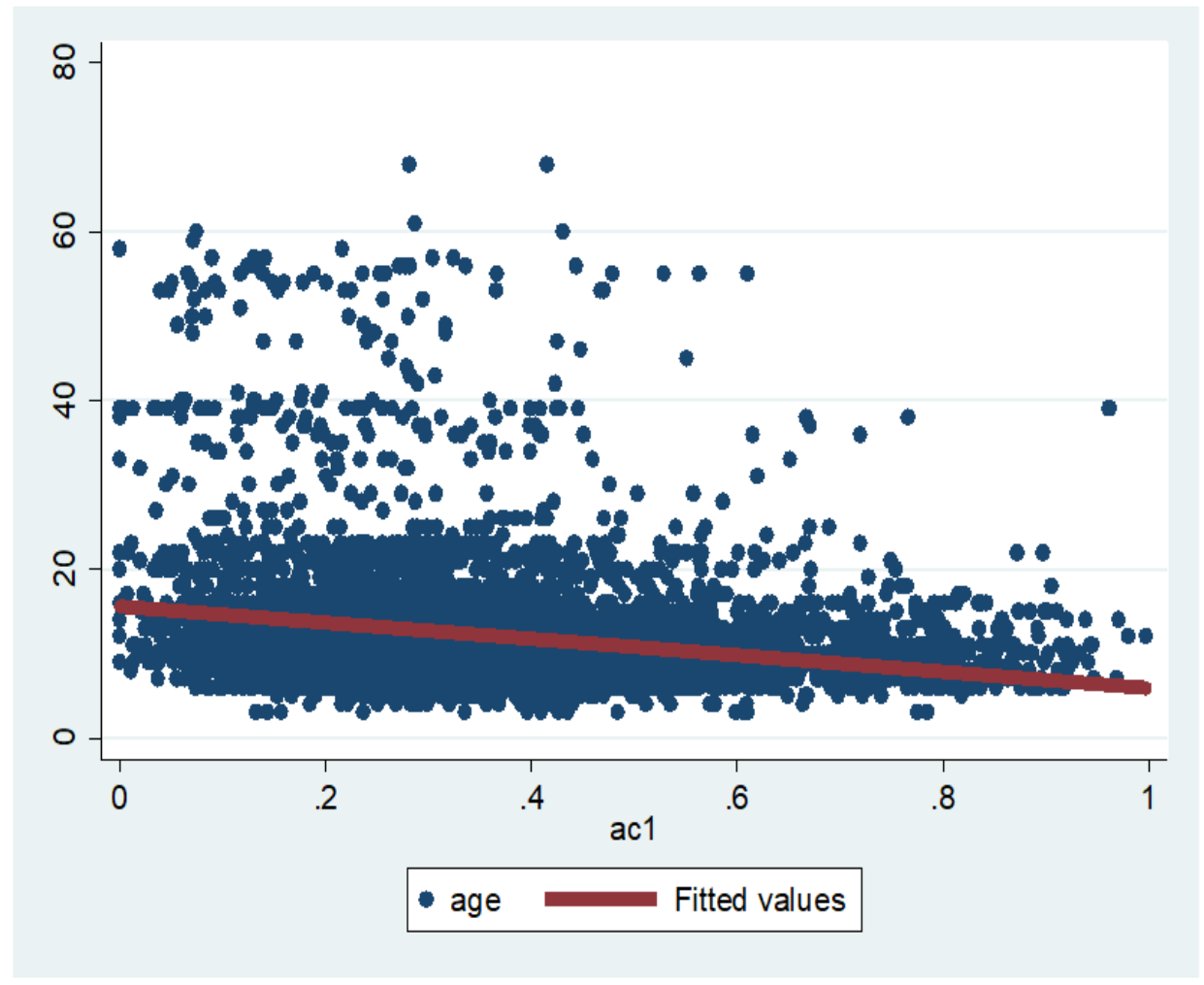

Source: Author

Similarly, the correlation between size of a firm and absorptive capacity of a Vietnamese firm is positive. The small firms have the biggest average DC over year, whereas the large firms possess the lowest one. It implies that absorptive capacity of the large firms is better than in the case of the small firms. Importantly, the difference between the small firms and the large firms is significant (0.368 comparing to 0.266). Interestingly, the medium-sized firms have quite good absorptive capacity with the value of 0.270 (Table 4). 
Table 4. Average DM of different sized-firms

\begin{tabular}{lccc} 
Variable & Obs & Mean & Std. Dev. \\
\hline Small & 40,433 & 0.3684 & 0.1617 \\
Medium & 1,443 & 0.2709 & 0.1734 \\
Large & 3,218 & 0.2668 & 0.1854 \\
Average AC & 45,094 & 0.3580 & 0.1667 \\
\hline
\end{tabular}

Source: author

More than 45000 firms are grouped into three groups: small, medium and large based on the number of workers. Then, mean difference between these groups is tested by using one-way analysis of variance (one-way ANOVA) and the result shows that mean difference among these groups is not coincident (Table 5).

Table 5. Annova test for mean difference

\begin{tabular}{lccccc} 
Source & Sum of square & df & Mean square & $F$ & Prob > F \\
\hline Between groups & 42.1153 & 2 & 21.0576 & 783.99 & 0.0000 \\
Within groups & 1211.125 & 45091 & 0.0269 & & \\
Total & 1253.24 & 45093 & 0.0278 & &
\end{tabular}

Bartlett's test for equal variances: $\operatorname{chi} 2(2)=130.4066$ Prob $>$ chi2 $=0.000$

Source: author

\section{Absorptive capacity and skilled workers}

The prerequisite of absorptive capacity is the pre-knowledge of an individual and an organization. Within a firm, a worker with higher skills certainly possesses more knowledge than those with low skill level. Normally, the skill of a worker is measured by education attainment or education degree. Unfortunately, this data is not available, hence, the wage of workers is used instead. It is argued that high-skilled workers can receive higher wage due to their better contribution to the firm. Therefore, higher wage can be interpreted as higher skill.

Once again, the measurement of absorptive capacity seems appropriate when the correlation between absorptive capacity and labor skill is significantly negative (Figure5). The lower value of average DC (the higher absorptive capacity) is, the higher skill of worker in domestic firms and vice versa. Note that this is only correlation that helps us see the phenomenon and it is not regression, so it is not possible to conclude if a high-skilled worker leads to better absorptive capacity or if good absorptive capacity leads to high-skilled individuals. 
Figure 6. Correlation between DC and wage

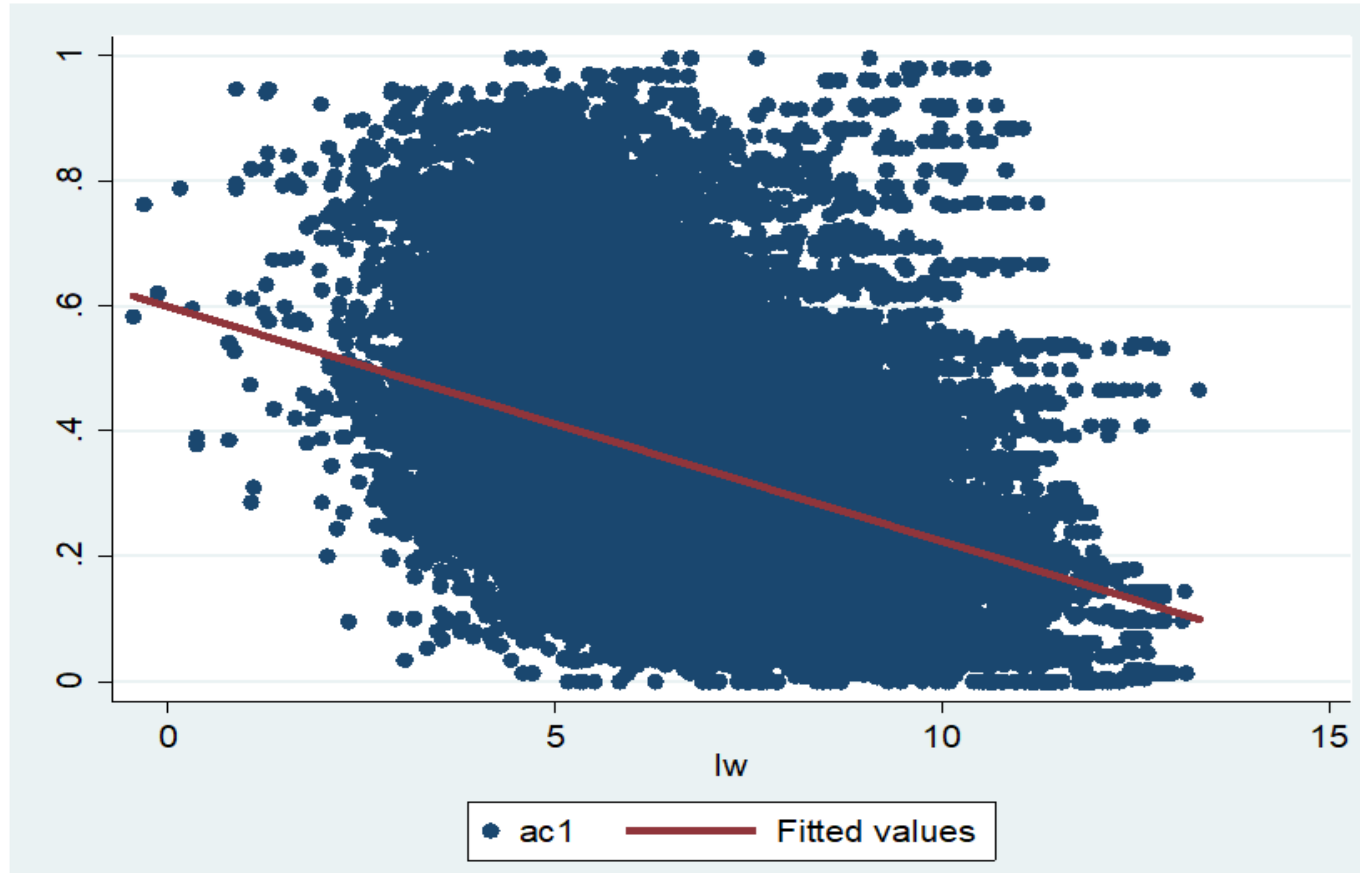

Source: Author

Absorptive capacity and technology level

Essentially, the relationship between R\&D activities and absorptive capacity is trivial. R\&D investment can positively affect capability of a firm to realize and apply new knowledge into practice. Basically, R\&D directly relates to technology level of a firm. However, data on R\&D and technology level of a Vietnamese firm in manufacturing sector is not possible to collect. Therefore, the study must find another proxy. It is premised that firms that use their own websites are more technologically advanced than those firms that do not. Consequently, the domestic firms are categorized based on whether they do or do not use websites and then their absorptive capacity is compared. This method is unable to capture entirely the correlation between absorptive capacity and technology level but to some extent it could be a good signal for it. Due to the lack of database, the paper uses website existence to assess the technology level of firms, however, it is necessary to use other criteria in further studies. 
Table 6. Average DC of using and non-using website domestic firms

\begin{tabular}{lccc} 
Variable & Obs & Mean & Std. Dev. \\
\hline Using web & 4,177 & 0.2429 & 0.1568 \\
Non-using web & 20,816 & 0.3416 & 0.1603 \\
\hline
\end{tabular}

Source: Author

In the Table 6, there can be seen a difference between web-using firms and firms that do not use websites. The average value of the former is lower than in the case of the latter and it indicates that absorptive capacity of the web-using ones is better. Implicitly, the result indicates that there is a correlation between technology level and absorptive capacity of Vietnamese manufacturing firms. It can be noticed that high-tech firms might absorb external knowledge better than low-tech firms. This difference is tested by t-test and the result confirms that the mean difference is significant (Table 7).

Table 7. t-test for mean difference

\begin{tabular}{lrrrrr} 
Source & Sum square & \multicolumn{1}{c}{ df } & Mean square & $F$ & Prob $>$ F \\
\hline Between groups & 33.9411 & 1 & 33.9411 & 1330.78 & 0.000 \\
Within groups & 637.3872 & 24991 & 0.0255 & & \\
Total & 671.3283 & 24992 & 0.0268 & & \\
\hline
\end{tabular}

Source: Author

Generally, it seems that the measurement of a firm's absorptive capacity based on the gap in persistent efficiency is reliable at least in the case of Vietnam when the expected correlations are approved. Therefore, it is claimed that this proxy for absorptive capacity can be used in the following studies in the case of Vietnam. However, duplicating is needed in other countries to improve the reliability.

\section{Conclusion}

There are substantial studies on absorptive capacity at the firm level and consequently there are various measures of absorptive capacity. However, finding a comprehensive proxy for it is difficult because different authors might look at different aspects of absorptive capacity. Approaches on absorptive capacity might vary but all of them to some extent converge to the point that: absorptive capacity of a firm is the internal capability and it also depends on external environment. Based on this, the present study attempts to simplify the measurement by defining absorptive capacity of a firm as a gap in persistent efficiency between this firm and the best firm in the same industry (normally the best one is a foreign one) and apply it to the case of Vietnamese manufacturing firms from 2007 to 2015. Persistent inefficiency is time-invariant and can repeat over times. It is unlikely to change unless there is a change in the firm's management mechanism (S. C. Kumbhakar et al., 2015). Hence, it can be a good proxy for the internal capacity of a firm. Among 23 sub-sectors of the Vietnamese manufacturing sector, the result shows that the domestic firms in the manufacture of 
tobacco product have the best absorptive capacity while firms that manufacture beverages do not have a good absorptive capacity. However, according to the author's knowledge, there is a lack of studies using the same method to proxy for absorptive capacity, therefore it is not possible to make a comparison. Consequently, the validity of the measurement is tested by considering the correlation between absorptive capacity and other-relating factors, including age and size of a firm, its technological level and the level of skill of its workers. All the correlations correspond with the expectations, hence this measurement to some extent could be a solid proxy for absorptive capacity at firm level. Due to insufficient data, one limitation of the paper is its dependence on the existence of firms' websites in order to evaluate their technological level. For further research, it is needed to find another proxy. Finally, the study has not figured out the casual relationship between absorptive capacity and above-mentioned factors and it is better to apply this method to some other cases to improve the validity.

Acknowledgement: The author really appreciates the guidance and support from prof. Pavel Ondrcka. Additionally, the suggestions of the two anonymous referees are greatly valuable for my work. Additionally, it is thankful to the project: "Thực trạng, định hướng và giải pháp phát triển kết cấu hạ tầng bền vững vùng Tây Nam Bộ" [Current states, orientations and solutions for sustainable infrastructure development in the Southwest region] - KHCN-TNB/14-19/X13 which provided this paper with useful inputs. The author is fully responsible for the remaining errors of the paper.

Funding: This work is supported by the project No. IGA/FaME/2018/019 FDI absorptive capacity and the factor determining FDI flows in developing countries of Asia and Africa.

Disclosure statement: No potential conflict of interest was reported by the author.

\section{References}

AHUJA, G., \& KATILA, R. (2001). Technological acquisitions and the innovation performance of acquiring firms: A longitudinal study. Strategic Management Journal, 22(3), 197-220. DOI: $10.1002 /$ smj.157

BADUNENKO, O., FRITSCH, M., \& STEPHAN, A. (2006). What Determines the Technical Efficiency of a Firm? The Importance of Industry, Location, and Size. Retrieved from http://econpapers.repec.org/RePEc:jen:jenasw:2006-33

BATTESE, G. E., \& COELLI, T. J. (1988). Prediction of firm-level technical efficiencies with a generalized frontier production function and panel data. Journal of Econometrics, 38(3), 387-399. DOI: 10.1016/0304-4076(88)90053-X

BATTESE, G. E., \& COELLI, T. J. (1992). Frontier Production Functions, Technical Efficiency and Panel Data: With Application to Paddy Farmers in India. Journal of Productivity Analysis, 3(1-2), 153-169.

BATTESE, G. E., \& COELLI, T. J. (1995). A Model for Technical Inefficiency Effects in a Stochastic Frontier Production Function for Panel Data. Empirical Economics, 20(2), 325-332. DOI: $10.1007 / \mathrm{BF} 01205442$

BEHERA, S. R. (2015). Do domestic firms really benefit from foreign direct 
investment? The role of horizontal and vertical spillovers and absorptive capacity. Journal of Economic Development, 40(2), 57-87.

BODMAN, P., \& LE, T. (2013). Assessing the roles that absorptive capacity and economic distance play in the foreign direct investment-productivity growth nexus. Applied Economics, 45(8), 1027-1039. DOI: 10.1080/00036846.2011.613789

COHEN, W. M., \& LEVINTHAL, D. A. (1989). Innovation and Learning: The Two Faces of R \& D. The Economic Journal, 99(397), 569-596.

COHEN, W. M., \& LEVINTHAL, L. A. (1990). Absorptive Capacity: A New Perspective on Learning and Innovation. Administrative Science Quarterly, 35(1), 128152. DOI: $\underline{10.2307 / 2393553}$

COHEN, W. M., \& LEVINTHAL, D. A. (1994). Fortune Favors the Prepared Firm. Management Science, 40(2), 227-251. DOI: 10.1080/00036846.2011.613789

CORNWELL, C., SCHMIDT, P., \& SICKLES, R. C. (1990). Production frontiers with cross-sectional and time-series variation in efficiency levels. Journal of Econometrics, 46(1-2), 185-200. DOI: 10.1016/0304-4076(90)90054-W

DYER, J. H., \& SINGH, H. (1998). Cooperative the Relational and Sources of Strategy Competitive Advantage. Academy of Management Review, 23(4), 660-679. DOI: 10.5465/amr.1998.1255632

FARRELL, M. J. (1957). The Measurement of Productive Efficiency. Journal of the Royal Statistical Society. Series A (General), 120(3), 253-290. DOI: $10.2307 / 2343100$

FENG, Y. W., \& WU, Y. (2006). Empirical study on the trade or FDI to influence technical efficiency. In Zhang, $\mathrm{H}$ and Zhao, RM and Chen, L (Ed.), Proceedings of the 2006 International Conference on Management Science and Engineering (pp. 524528). PO BOX 893, MARRICKVILLE, NSW 2204, AUSTRALIA: ORIENT ACAD FORUM.

FLÔRES, R. G., FONTOURA, M. P., \& GUERRA SANTOS, R. (2007). Foreign Direct Investment Spillovers in Portugal: Additional Lessons from a Country Study. The European Journal of Development Research, 19(3), 372-390. DOI: $\underline{10.1080 / 09578810701507126}$

FOSFURI, A., \& TRIBO, J. A. (2008). Exploring the antecedents of potential absorptive capacity and its impact on innovation performance. Omega, 36(2), 173-187. DOI: $10.1016 /$ j.omega.2006.06.012

GHALI, S., \& REZGUI, S. (2011). FDI Contribution to Technical Efficiency in the Tunisian Manufacturing Sector: Evidence from Micro-panel Data. International Economic Journal, 25(2), 319-339. DOI: 10.1080/10168737.2010.504215

GIRMA, S., GORG, H., \& PISU, M. (2008). Exporting, linkages and productivity spillovers from foreign direct investment. Canadian Journal of Economics, 41(1), 320340. DOI: $10.1111 / \mathrm{j} .1365-2966.2008 .00465 . \mathrm{x}$

GREENE, W. H. (2005). Fixed and Random Effects in Stochastic Frontier Models. Journal of Productivity Analysis, 23(1), 7-32. DOI: 10.1007/s11123-004-8545-1 
IMBRIANI, C., PITTIGLIO, R., REGANATI, F., \& SICA, E. (2011). How mисh do technological gap, firm size, and regional characteristics matter for the absorptive capacity of Italian enterprises?

JABBOUR, L., \& MUCCHIELLI, J.-L. (2007). Technology transfer through vertical linkages: The case of the Spanish manufacturing industry. Journal of Applied Economics, 10, 115-136.

KUMBHAKAR, S. (1987). The specification of technical and allocative inefficiency in stochastic production and profit frontiers. Journal of Econometrics, 34(3), 335-348. DOI: $\underline{\text { 10.1016/0304-4076(87)90016-9 }}$

KUMBHAKAR, S. C., LIEN, G., \& HARDAKER, J. B. (2014). Technical efficiency in competing panel data models: A study of Norwegian grain farming. Journal of Productivity Analysis, 41(2), 321-337. DOI: 10.1007/s11123-012-0303-1

KUMBHAKAR, S. C., WANG, H.-J., \& HORNCASTLE, A. P. (2015). A Practitioner's Guide to Stochastic Frontier Analysis Using Stata. Cambridge University Press.

LANE, P. J., KOKA, B. R., \& PATHAK, S. (2006). The reification of absorptive capacity: A critical review and rejuvenation of the construct. Academy of Management Review, 31(4), 833-863. DOI: 10.5465/amr.2006.22527456.

LANE, P. J., \& LUBATKIN, M. (1998). Relative absorptive capacity and interorganizational learning. Strategic Management Journal, 19(5), 461-477. DOI: 10.1002/(SICI)1097-0266(199805)19:5<461::AID-SMJ953>3.0.CO;2-L

MARTINKENAITE, I., \& BREUNIG, K. J. (2015). The emergence of absorptive capacity through micro-macro level interactions. Journal of Business Research, 69(2), 700-708. DOI: $\underline{10.1016 / j . j b u s r e s .2015 .08 .020}$

MINH, N. K., LONG, G. T., \& THANG, B. N. (2007). Technical Efficiency of Small and Medium Manufacturing Firms in Vietnam: Parametric and Non-Parametric Approaches *. The Korean Economic Review, 23(1), 187-221.

MOWERY, D. C., \& OXLEY, J. E. (1995). Inward technology transfer and competitiveness: the role of national innovation systems. Cambridge Journal of Economics, 19(1), 67-93.

RAO, H., \& DRAZIN, R. (2002). Overcoming Resource Constraints on Product Innovation by Recruiting Talent from Rivals: A Study of the Mutual Fund Industry, 1986-94. The Academy of Management Journal, 45(3), 491-507.

SCHMIDT, P., \& SICKLES, R. (1984). Production Frontiers and Panel Data. Journal of Business \&amp; Economic Statistics, 2(4), 367-374.

SILAJDZIC, S., \& MEHIC, E. (2015). Knowledge Spillovers, Absorptive Capacities and the Impact of FDI on Economic Growth: Empirical Evidence from Transition Economies. Procedia - Social and Behavioral Sciences, 195, 614-623. DOI: 10.1016/j.sbspro.2015.06.142

SØRENSEN, J. B., \& STUART, T. E. (2000). Aging, Obsolescence, and Organizational Innovation. Administrative Science Quarterly, 45(1), 81-112. DOI: $\underline{10.2307 / 2666980}$ 
SZULANSKI, G. (1996). Exploring internal stickiness: Impediments to the transfer of best practice within the firm. Strategic Management Journal, 17(S2), 27-43. DOI: $10.1002 /$ smj.4250171105

TRAN D.T., PHAM S.A., \& VU H.D. (2014). Kinh te Vietnam: nhung van de cua khu vuc doanh nghiep [ Vietnamese economy: some issues of enterprises]. Khoa hoc xa hoi Publishing. Hanoi.

TSAI, W. P. (2001). Knowledge transfer in intraorganizational networks: Effects of network position and absorptive capacity on business unit innovation and performance. ACADEMY OF MANAGEMENT JOURNAL, 44(5), 996-1004. DOI: $\underline{10.2307 / 3069443}$

TU, Q., VONDEREMBSE, M. A., RAGU-NATHAN, T. S., \& SHARKEY, T. W. (2006). Absorptive capacity: Enhancing the assimilation of time-based manufacturing practices. Journal of Operations Management, 24(5), 692-710. DOI: 10.1016/j.jom.2005.05.004

VU, H. D. (2016). Technical efficiency of FDI firms in the Vietnamese manufacturing sector. Review of Economic Perspectives, 16(3). DOI: 10.1515/revecp-2016-0013

VU, H. D., \& LE, V. H. (2017). FDI spill-overs, absorptive capacity and domestic firms' technical efficiency in Vietnamese wearing apparel industry. Acta Universitatis Agriculturae et Silviculturae Mendelianae Brunensis, 65(3), 1075-1084. DOI: 10.11118/actaun201765031075

ZAHRA, S. A., \& GEORGE, G. (2002). Absorptive Capacity: A Review, Reconceptualization, And Extension. Academy of Management Review, 27(2), 185-203. DOI: $10.5465 / \mathrm{amr} .2002 .6587995$ 


\section{Appendix A. Fixed effect regression}

R-square:

Number of Obs $=52435$

$$
\begin{aligned}
& \text { Within }=0.1256 \\
& \text { Between }=0.8055 \\
& \text { Overall }=0.6006
\end{aligned}
$$

$$
\operatorname{Corr}\left(u \_i, X\right)=0.3075
$$

$\begin{array}{lll}\mathrm{F}(5,45864) & = & 1317.56 \\ \text { Prob }>\mathrm{F} & = & 0.0000\end{array}$

\begin{tabular}{ccccccc} 
LnY & Coef. & Std. Err. & $t$ & $P>t$ & {$[95 \%$ Conf. } & Interval] \\
\hline LnL & 0.5681 & 0.0318 & 17.84 & 0 & 0.5057 & 0.6305 \\
LnK & 0.2811 & 0.0274 & 10.23 & 0 & 0.2272 & 0.3349 \\
LnL*LnL & 0.0232 & 0.0051 & 4.53 & 0 & 0.0132 & 0.0333 \\
LnK*LnK & -0.0024 & 0.0024 & -0.98 & 0.329 & -0.007 & 0.0024 \\
LnL*LnK & -0.009 & 0.0053 & -1.84 & 0.066 & -0.0201 & 0.0006 \\
cons & 4.3966 & 0.0985 & 44.62 & 0 & 4.2035 & 4.5898 \\
sigma_u & 0.8529 & & & & & \\
sigma_e & 1.2129 & & & \\
rho & 0.3309 & & &
\end{tabular}

Source: Author 


\section{Appendix B. Number of domestic and foreign firms over year}

Name of industry

Manufacture of food products

Manufacture of beverages

Manufacture of tobacco products

Manufacture of textiles

Manufacture of wearing apparel

Manufacture of leather and related products

Manufacture of wood and of products of wood and

Manufacture of paper and paper products

Printing and reproduction of recorded media

Manufacture of coke and refined petroleum

Manufacture of chemicals and chemical products

Manufacture of pharmaceuticals, medicinal

Manufacture of rubber and plastics products

Manufacture of other non-metallic mineral products

Manufacture of basic metals

Manufacture of fabricated metal products, except

Manufacture of computer, electronic and optical

Manufacture of electrical equipment

Manufacture of machinery and equipment n.e.c

Manufacture of motor vehicles; trailers and semitrailers

Manufacture of other transport equipment

Manufacture of furniture

Other manufacturing

Repair and installation of machinery and equipment
Domestic Foreign observation observation

$6,124 \quad 650$

$1,313 \quad 86$

$83 \quad 8$

$2,444 \quad 486$

$4,511 \quad 1,394$

$1,314 \quad 548$

$1,658 \quad 164$

$2,262 \quad 277$

$3,466 \quad 84$

$34 \quad 15$

$1,975 \quad 388$

$504 \quad 43$

$4,928 \quad 1,019$

$1,875 \quad 165$

$764 \quad 54$

$5,121 \quad 696$

$432 \quad 272$

$984 \quad 213$

$1,414 \quad 79$

$267 \quad 92$

$398 \quad 136$

$1,762 \quad 159$

$940 \quad 293$

$521 \quad 20$

Source: Author 
